\title{
Revisão Sistemática Sobre a Produção da Paz
}

\author{
Systematic Review about the Production of Peace \\ Revisión Sistemática Sobre la Producción de la Paz
}

\author{
André Amorim Martins \\ Coordenador da Pesquisa, psicólogo, professor do Curso de Psicologia da Universidade do Estado de Minas Gerais, \\ Unidade Divinópolis. E-mail: andremartinsufrj@gmail.com \\ Cristina Silva Gontijo \\ Daniela Almeida Silva Brum \\ Cristina Alvarenga Santos \\ Fernanda Borges Henrique \\ Tânia Maria Alvarenga Alves \\ Curso de Psicologia da Universidade do Estado de Minas Gerais, Unidade Divinópolis
}

Resumo

Este artigo propõe fazer uma revisão sistemática sobre o tema produção da paz na literatura disponibilizada no banco de dados BVS-Psi a fim de fomentar a pesquisa "A atuação do serviço público na produção da paz". Este estudo se originou na Rede da Paz do município de Divinópolis/MG; programa que tinha como objetivo convergir às ações dos poderes públicos para uma sociedade de paz. Utilizamos como método para a revisão sistemática, quatro passos: 1 ) objetivo da pesquisa; 2) definição dos termos ou palavras-chave; 3) seleção dos estudos encontrados em convergência com a pesquisa; 4) escolha de estudos fidedignos e com validade. Para a revisão selecionamos como base 15 artigos que serviram como ferramentas de discussão, apreensão de conceitos sobre a paz, bem como para a utilização no momento da aplicação da entrevista semi-estruturada nos informantes chaves. Utilizaremos, no decorrer da pesquisa, o conceito de paz como aquilo que proporciona o respeito pela vida e pelas diferenças de existência.

Palavras-chave: paz; estado; Psicologia; revisão.

Abstract

This article aims to carry out a systematic review on the theme "production of peace" from the available literature in the database BVS-Psi to improve the research "The acting of the public service into the production of peace". The Net of Peace in the city of Divinópolis/MG was the source of such study, since the Net of Peace aims to turn the actions from the public authorities to a society of peace. The method applied was the four steps for a systematic review: 1) research aims; 2) terminology definition; 3) selection of bibliographical base; 4) to choose reliable studies. The systematic review has considered the selection of 15 basic articles to foment the discussion, apprehension of concepts about the peace and also for the use at the moment of the application of the semi-structured interview in the key informants. The concept of Peace used at this research is "that provides the respect for the life and for the several differences of existence".

Keywords: peace, State, Psychology, review.

Resumen

Este artículo propone realizar una revisión sistemática sobre el tema producción de la paz en la literatura disponible en la base de datos BVS-Psi a fin de fomentar la investigación "La actuación del servicio público en la producción de la paz”. Este estudio se originó en la Rede da Paz del municipio de Divinópolis/MG; programa que tenía como objetivo converger a las acciones de los poderes públicos para una sociedad de paz. Utilizamos como método para la revisión sistemática, cuatro pasos: 1) objetivo de la investigación; 2) definición de los términos o palabras clave; 3) selección de los estudios encontrados en convergencia con la investigación; 4) Elección de estudios fidedignos y con validad. Para la revisión seleccionamos como base 15 artículos que sirvieron como herramientas de discusión, aprensión de conceptos sobre la paz, bien como para la utilización en el momento de la aplicación de la entrevista semiestructurada en los informantes claves. Utilizaremos, en el transcurso de la investigación, el concepto de paz como aquello que proporciona el respeto por la vida y por las diferencias de existencia.

Palabras clave: paz; estado; Psicología; revisión. 
A produção da paz enfrenta grandes desafios no cenário internacional. Desafios que passam pela conceituação de paz, definição dos objetivos que exerce no cotidiano, novas formas de subjetivações, etc. A princípio, liga-se a paz como uma solução para a violência, o que faz com que essas palavras (paz e violência) sejam no senso comum uma díade eterna.

Ao iniciarmos a discussão sobre a paz, nos deparamos com a questão: a paz é produzida ou promovida? Foucault (1999) nos apresenta que o Estado Moderno produz as ações sobre a vida das pessoas, um estado produtor. Esta produção tende a aumentar a força produtiva, as relações de vida, organizando as formas como a sociedade se estrutura para fazer com que a população viva com mais equidade. Partimos do princípio que a paz deve ser produção de paz, deve ser a paz em ação. Isto significa imbuir-se de uma consciência de valores sobre o sujeito social. A paz é construída e não elimina conflitos ou oposições, mas pressupõe a resolução dos mesmos, trabalhando o dissenso, respeitando as diferenças, mudando radicalmente o paradigma que dá sustentação ao modelo civilizatório de segmentação. A produção de paz analisa os modelos exitosos existentes e busca analisar as tensões que nomeamos de "violência" ou "barbárie" que ocorrem de ordem física, sexual, étnica, psicológica, de classe, das palavras e de ações.

O principal instrumento para discutir uma sociedade que tenha a paz como eixo estruturante foi a Declaração Universal dos Direitos Humanos (1948) e seus desdobramentos. A Assembleia Geral das Nações Unidas proclamou, em 1997, o ano de 2000 como o Ano Internacional da Cultura de Paz. Em 1998, declarou o período de 2001 a 2010 a "Década Internacional da Cultura de Paz e Não-Violência para as Crianças do Mundo". Assim, fomos chamados a pesquisar uma temática universal, elevando o debate sobre a convivência entre todas as pessoas de diferentes culturas, credos, opiniões e raças.

Além da dor e do sofrimento humano, a violência gera um mal-estar generalizado na sociedade - decorrente do medo, das graves repercussões na qualidade de vida e do grande impacto econômico pelas vítimas e custos reais e também pelos gastos e perdas que sua prevenção e medo obrigam.

A violência é um fenômeno complexo, dinâmico, desafiador e vem exigindo esforços para o seu entendimento, prevenção e superação numa sociedade caracterizada por extremas desigualdades, como a brasileira. No Brasil, a taxa de homicídios é de 32,4 para cada 100 mil habitantes, sendo uma das maiores taxas dos países americanos. Em dados de assassinatos no mundo, $80 \%$ das vítimas são homens, $65 \%$ homens com idade entre 15 e 49 anos. Segundo a Organização das Nações Unidas - ONU, o maior impulsionador destas taxas é o acesso a armas de fogo (ONU, 2016).

Dessa forma, buscamos contribuir, a partir da ciência psicológica e suas interfaces, com essa permanente responsabilidade social, desde a formação de profissionais (através dos artigos publicados no Banco Virtual em Saúde - Psicologia Brasil) até a produção de conhecimento científico sobre o tema da produção da paz.

\section{Método}

A proposta de revisão sistemática de Sampaio e Mancini (2007) foi utilizada. Para as autoras,

a revisão sistemática é uma forma de pesquisa que utiliza como fonte de dados à literatura sobre determinado tema. Esse tipo de investigação disponibiliza um resumo das evidências relacionadas a uma estratégia de intervenção específica, mediante a aplicação de métodos explícitos e sistematizados de busca, apreciação crítica e síntese da informação selecionada (p.84).

Conforme as autoras, nos quatro passos propostos, o primeiro refere-se ao objetivo da 
pesquisa; o segundo a definição dos termos ou palavras-chave assim como a base de dados; o terceiro é a seleção dos estudos encontrados em convergência com a pesquisa e o quarto, é a escolha de estudos fidedignos e com validade.

O objetivo é "contribuir, a partir da ciência psicológica e suas interfaces, com essa permanente responsabilidade social, desde a formação de profissionais (através dos artigos publicados no Banco Virtual em Saúde - Psicologia Brasil) até a produção de conhecimento científico sobre o tema da produção da paz". Assim, o Banco Virtual de Saúde Psicologia ULAPSI Brasil (BVS Psi) foi acessado em 15 de dezembro de 2011 e inserimos a palavra-chave Paz. Não foi estipulada data referente à publicação dos artigos.

O caminho percorrido foi o seguinte: acesso ao site www.bvs-psi.org.br - link TEMAS e opção Psicologia. Com a palavra-chave PAZ, foram apresentados, no Index Psi Revista Técnico Científicas, 65 artigos; como refinador de busca, o Descritor Psi Português e foi gerada uma nova contagem de 87 artigos. Artigos com acesso restrito ou sem o texto completo no banco de dados foram eliminados e os demais foram direcionados para os pesquisadores, para que realizassem o fichamento dos artigos que tinham convergência com os objetivos da pesquisa, o que culminou no resultado final de 15 artigos, com os quais foi realizada esta revisão sistemática. Foram realizados quatro seminários nos meses de abril e maio de 2011 para apresentação dos conteúdos destes artigos e nivelamento dos pesquisadores.

\section{Resultados}

Dentre os artigos selecionados, tivemos um período de publicações entre 1998 a 2009. Sinal de convergência com a solicitação de fomentar o tema na Década da Paz. Somente uma autora esteve presente em três artigos. Os demais realizaram 1 (uma) produção com base no tema sobre a paz. As palavras-chave mais utilizadas foram: $\mathrm{Paz}$ (seis vezes); Violência (seis vezes); Educação (cinco vezes); Direitos Humanos (duas vezes). As demais palavras-chave apareceram de forma isolada sinalizando que a temática dos artigos foi bem diversa: escolar, clínica, produção de conceitos, política.

Conseguimos categorizar em quatro campos de discussão: conceitos de paz; paz e educação; a paz enquanto instituição e a Psicologia para a paz. Trabalharemos estes conceitos separadamente de forma didática, mas sabendo que estes campos são a sinergia da discussão sobre a paz.

\section{Conceitos de paz}

Analisando as concepções ou tradições de paz ao longo da história, Souza, Mocelim, Trindade, e Sperb (2006) propõem inicialmente que a concepção ocidental de paz que predomina atualmente é "ausência de algo" (de guerra, violência, conflito) ou como intervalo entre guerras. Com isso, os autores salientam que esta leitura seja superada em direção a uma conceituação mais positiva calcada em experiências humanas como a justiça e a igualdade.

Souza (2007), ao analisar os trabalhos que se dedicam à paz, apreende a partir deles que há três maneiras básicas de alcançá-la: através do peacemaking, com o uso de técnicas de resolução de conflito para promover reconciliação das partes envolvidas; do peacekeeping, com a obtenção de paz pela força (por exemplo, quando o exército é chamado para interferir em conflitos armados ou, no caso da realidade brasileira, em rebeliões nos presídios ou contra traficantes de drogas); ou do peacebuilding, através do qual se pretende despertar o "desejo por paz na mente das crianças". Galtung (1969, citado por Souza et al., 2006), considera que o conceito de paz possui duas dimensões: "paz negativa" (ausência de violência física ou direta) e "paz positiva" (quando há cooperação, justiça, solidariedade). A paz positiva inclui ainda a "ausência de violência estrutural ou indireta", definida como "uma forma de violência implícita que permeia as 
estruturas socioeconômicas e políticas de uma sociedade, sendo tão danosa quanto à violência direta, uma vez que também ofende e mata, porém, lentamente, privando os indivíduos da possibilidade de satisfazerem necessidades básicas à sobrevivência" (Christie et al., 2001 citado por Souza et al., 2006, p.14).

Em pensamento similar, Maldonado (1997, citado por Souza et al., 2006) afirma que a construção da paz e a redução da violência se dão por meio da participação da comunidade, do reforço de características de paz existentes em diversas culturas e indivíduos e de novos meios de resolução de conflitos. Para a autora, a prevenção da violência deve começar nos pequenos atos do cotidiano, estendendo-se até interações sociais mais amplas. Percebe-se aí que a ação vai do "micro" para o "macro" e depende do interesse dos próprios indivíduos que compõem a sociedade.

A visão de paz para D’Ambrosio (2001), diz que "há várias maneiras, técnicas, habilidades de explicar, de entender, de lidar e de conviver com (matema) distintos contextos naturais e socioeconômicos da realidade (etnos)" (D’Ambrosio, 2001, pág. 13).

Frente a isto, o autor defende que a busca de paz total deve ter como base uma educação voltada para a paz, onde o conhecimento esteja subordinado ao humanismo: se a ciência tem como objetivo primeiro servir ao homem, se deixar de fazê-lo perde sua essência e sentido de existir.

Fischmann (2001) apresenta o conceito

[...] a paz, não é um estado letárgico, ou a renúncia ao poder, mas a expressão mais viva e vigorosa do real poder, o que se articula como decisão e ato de vontade, de quem deseja construir. Por isso, o fortalecimento do ser humano, individual e coletivamente - o que inclui, como tratado por Moore Junior citado por Fischmann (2007), a capacidade de se indignar e de resistir contra injustiças - conta com a Declaração Universal dos Direitos Humanos como instrumento, como agenda comum da humanidade (p. 74).

Pode-se verificar a paz enquanto uma produção e a paz em ação é uma proposta nesse embasamento teórico, através das ideias da ONU e dos autores acima. A perspectiva apresentada reflete que a humanidade se faz a partir das ações e das relações humanas, nas suas diversidades. Com isso, a proposição de uma universalidade passa pelas tensões, pela tolerância entre os povos e o direito a vida como instâncias primárias.

\section{Paz enquanto instituição - ONU - Direitos Humanos}

Segundo os dados históricos colhidos por Fischmann (2001), em 1945, a Organização das Nações Unidas (ONU) foi criada e expressava "o reconhecimento da dependência mútua e da necessidade impostergável de uma ação conjunta de diferentes povos" (p.67). Em 1948, a Assembleia da ONU Declaração Universal dos Direitos Humanos (DUDH) prossegue nesta mesma linha de construção da relação entre os povos, mas deixa evidente a importância de cada pessoa para a espécie humana.

Uma construção que Fischmann (2001) nos apresenta é que para a comemoração dos 50 anos da ONU, a Assembleia decidiu que 1995 seria o Ano Internacional da Tolerância. Segundo a autora, “a decisão vinculava-se ao reconhecimento humilde e apropriado de que, cinquenta anos após sua criação, a Organização das Nações Unidas se encontrava longe de atingir o objetivo para o qual havia sido criada, ou seja, o de alcançar a paz mundial" (p.70). Foi proposto como tema para as discussões o conceito de tolerância.

Segundo Fischmann (2001), o conceito foi debatido em diversas partes do mundo e com isso trouxe grandes debates e críticas. "Houve quem lembrasse que seria até indesejável 'ser tolerado', quando o mínimo que se espera é ser respeitado" (p. 70). Para os fins da Instituição, em 1995, a ONU apresenta a Declaração Mundial de Princípios sobre a Tolerância e apresenta como primeiro artigo:

A tolerância é o respeito, a aceitação e o apreço da riqueza e da diversidade das culturas de nosso 
mundo, de nossos modos de expressão e de nossas maneiras de exprimir nossa qualidade de seres humanos. É fomentada pelo conhecimento, abertura de espírito, a comunicação e a liberdade de pensamento, de consciência e descrença. A tolerância é harmonia na diferença. Não só é um dever de ordem ética; é igualmente uma necessidade política e de justiça. A tolerância é uma virtude que torna a paz possível e contribui para substituir uma cultura de guerra por uma cultura de paz (Fischmann, 2001, p.70)

Lévy (2004) aponta o caráter ambíguo das instituições: instâncias simbólicas e imaginárias e, ao mesmo tempo, instâncias de poder. Isto porque, sob o manto de algumas instituições as pessoas justificam seus atos de violência, como se tivessem autorização para liberar suas pulsões por "receberam ordens", por ser "em nome" da Igreja ou "servindo" a nação. Contudo, ainda há situações em que as instituições não só não toleram certas ações, como encorajam outras, sutilmente, e também prescrevem abertamente o que se deve fazer.

$\mathrm{O}$ autor enxerga um problema em focalizar a atenção nas violências individuais, "privadas" e particularmente em seus autores: isto leva ao esquecimento das violências exercidas pelas próprias instituições - sejam elas estatais, espirituais, culturais ou econômicas - sob o manto de sua suposta legitimidade, na qualidade de garantidoras da ordem e da paz civis. Assim, a "privatização da violência" é um engodo para que se ignore a participação das instituições nestes eventos. Porém, como ressalta o autor, se tais casos de violência têm tanto espaço na mídia, é justamente porque são agressões intoleráveis para instituições como a família e a religião. Daí o envolvimento de representantes da Lei e do Direito em situações em que estes são responsáveis ou cúmplices de crimes que dilaceram as famílias e desonram as cidades, ao invés de estarem exercendo seus papéis de protetores.

Ainda que o Estado, junto a seus diversos componentes ocupe um lugar central (apesar de cada vez menor), eles partilham o poder com outras instituições, oficiais ou oficiosas, formais ou clandestinas - econômicas, espirituais e culturais, educativas. Essas instituições (...) podem estar fundados na força e na ameaça físicas, na força moral e cultural, ou ainda no dinheiro, no controle das riquezas e dos modos de produção, ou na difusão e elaboração da informação e do saber (Lévy, 2004, p. 198).

\section{Paz e educação}

A educação para a paz, há mais de 80 anos, vem sendo discutida e estudada por educadores, filósofos, sociólogos, antropólogos e psicólogos de diversos países, sob ênfases variadas (Souza \& Sperb, 2006).

No âmbito escolar ocorrem encontros de diversas culturas que se entrelaçam; também é um lugar que o subjetivo do indivíduo se instala com divergências e conflitos.

Para Souza e Sperb (2006), a comunicação da Psicologia Escolar com a Cultura da Paz visa meios para promover a escuta através de um espaço específico criado neste mesmo contexto. Lócus, que não só para formar profissionais, mas com o olhar da Psicologia Escolar, que vem para avaliar crenças que consequentemente trazem determinados comportamentos, ajuda na construção de promoção da Cultura de Paz para "um processo de transformação individual e social” (Souza et al., 2006, p.16).

Para Sposito (2001) citado por Souza (2007), "no início da década de 1980, a preocupação com relação à violência nas escolas baseava-se na proteção das unidades escolares contra a depredação do patrimônio e contra a presença de pessoas estranhas, advindas da periferia, qualificadas como marginais e delinquentes" (p.131). Conforme a autora, não se questionavam as formas de sociabilidade entre os estudantes, embora nas discussões houvesse críticas a práticas autoritárias consideradas violentas, através da busca por um modelo mais democrático de gestão que envolvesse alunos, pais e comunidade. Isso só foi exposto a partir dos anos 1990.

Segundo D'Ambrosio (2001), em todas as culturas em todos os tempos são criados e 
desenvolvidos instrumentos e habilidades para explicar e entender a natureza, como resposta a necessidades de sobrevivência e transcendência em ambientes dos mais diversos. Desta forma, o conhecimento está subordinado a um contexto natural, social e cultural. Ignorar tal característica não atende ao objetivo primordial da educação, que é o de dar subsídios aos povos para alcançarem uma melhor qualidade de vida e maior dignidade da humanidade como um todo. Isto permitiria preservar a diversidade, mas eliminando a desigualdade discriminatória e dando origem a uma nova organização da sociedade.

Um dos apontamentos do autor para que seja possível a construção de uma paz total é que cada indivíduo se reconheça e se integre na sua sociedade, na humanidade, na natureza e no cosmos. Neste sentido, defende que "a Educação é a estratégia mais importante para levar o indivíduo a estar em paz consigo mesmo e com o seu entorno social, cultural e natural e a se localizar numa realidade cósmica" (D’Ambrosio, 2001, p. 02).

Portanto, a educação para a paz constitui-se como tema transversal para alcançar os seus meios e fins, visando maior consideração sobre aspectos da aprendizagem e do ensino, do humano para outro humano.

\section{Psicologia para a paz}

A Psicologia para a Paz é pouco conhecida no Brasil, porém é um campo concreto de estudos e práticas em Psicologia que aborda as temáticas da paz, da guerra, do conflito e da violência. Um aprofundamento em estudos destas temáticas possivelmente daria subsídios aos psicólogos e a outros profissionais da saúde para a construção de uma cultura de paz. O primeiro a abordar o envolvimento da Psicologia com a paz foi William
James, por meio de duas palestras que proferiu acerca da paz e da guerra. Correspondências foram trocadas por outros intelectuais como Sigmund Freud, Jean Piaget e Albert Einstein, cujas concepções de paz se referiam à ausência de guerras, o que sem dúvida é fruto do momento histórico-cultural em que viveram (Souza et al., 2006).

Uma busca realizada pelos autores acima, nas bases de dados disponíveis, conseguiu encontrar apenas dois trabalhos, em Psicologia, que falassem diretamente de promoção da paz, quer dizer, que tivesse como objetivo ou como um dos objetivos do trabalho, promover a paz. A partir de outra pesquisa realizada nestas mesmas bases de dados, ficou evidente que a paz é um tema pouco explorado no Brasil: apenas três estudos psicológicos sobre atitudes em relação à paz, à guerra e à violência foram localizados.

Os autores Souza et al. (2006) realizaram entrevistas com estudantes de Psicologia de uma universidade do Rio Grande do Sul para verificar o que estes pensavam sobre a relação entre Psicologia e Paz. A definição de paz dada pelos participantes foi a partir do individual e social e estes afirmaram desconhecer exemplos do envolvimento da Psicologia com a Paz. Apesar disto, salientaram que a Psicologia pode contribuir para a paz como prática que visa o bem-estar do indivíduo ou como ciência que estuda o ser humano e sua relação intrapessoal (paz interior) e com as pessoas, interpessoal, (paz social e mundial).

Pode-se constatar que tal situação coopera para o que se considera ser expressivo na pesquisa, mesmo não tendo como foco principal a relação Psicologia e a Paz, sendo esse um ponto de interesse específico. Isso leva-nos ao compromisso embutido do fazer e saber psicológicos, mas que precisa tornar-se mais explícito na própria Psicologia.

\section{Discussão}

Frente aos achados nesta revisão sistemática, o tema de produção da paz demonstrou-se complexo, em desenvolvimento e perpassando questões intrínsecas às estruturas sociais firmadas, certamente será um trabalho para longo prazo. Para isso, é preciso desde já pensar na construção 
de uma cultura de paz e olhar para a realidade de uma forma mais global, entendendo a dinâmica que este tema exige.

Como dito no início, maiores estudos em Psicologia para a Paz e aprofundamentos nas discussões de paz poderiam dar melhores subsídios aos profissionais de saúde, educação, cultura, esporte e assistência social para melhor lidar com estas questões, fazendo também com que seu trabalho seja mais efetivo, atinja a população a quem se propõe servir.

Outro destaque é a preocupação - que educadores estão trazendo para este cenário - ao colocar a escola como uma importante ferramenta de transformação social. Isso reflete nos títulos dos artigos: "Administração de conflitos sem violência na escola", "Educação para o diálogo em Martin Buber", "Paz, educação matemática e etnomatemática", "Cultura da paz e psicologia escolar no contexto da instituição educativa".

Destacamos que pretendemos adotar o conceito de paz enquanto o respeito pela vida e das suas diferenças de manifestação. Na pesquisa de campo, esperamos encontrar conceitos similares e até a utilização de formatações conceituais destes autores estudados. Assim como, as experiências apresentadas na literatura (escola, em grupos sociais, famílias) nos servirão de cenários do que podemos encontrar no cotidiano do serviço público.

Visto que nos artigos, não raro, foi posto que a "Promoção de Paz" não seja ausência de conflitos. Entretanto, a promoção é encontrada nos conflitos, nas diferentes escutas, nos mais variáveis contextos e nas culturas. Como por exemplo, no âmbito escolar, familiar, na construção de uma sociedade e até mesmo dentro de um espaço militar.

A promoção da paz é um lócus da vida, no qual o sofrimento, conflitos, dor, mudanças são personagens da construção deste espaço. É importante ressaltar que na hora da promoção de paz há de se considerar os diversos tipos de cultura, linguajares e devires. Pois, são neles que a cultura de paz é construída.

\section{Considerações finais}

Esta revisão sistemática nos proporcionou um método de trabalho com os artigos de interesse da pesquisa que nos auxiliou na sistematização dos materiais a serem trabalhados pelos pesquisadores. No momento de nivelamento dos conceitos e de aprofundamento teórico, é de extrema importância proporcionar aos pesquisadores um contato ampliado com as discussões realizadas no meio acadêmico ao longo dos tempos.

A utilização do banco de dados BVS - Psi foi extremamente rica, por proporcionar uma quantidade de material considerado necessário para o trabalho. Muitos artigos dispararam a busca dos seus referenciais bibliográficos, o que culminou em mais leituras, discussões e criação de novas hipóteses.

Ter como objeto a produção da paz nos mostrou que o tema ficou delimitado em um período histórico. Esta temática ainda precisa de maiores aprofundamentos, entendermos qual o legado desse movimento criado e as formas atuais de produção de paz. 


\section{Referências}

Carvalho, J. S. (1998). A cátedra da USP/ UNESCO e a formação de professores. Cadernos de Pesquisa, (104), p. 35-75. Recuperado de http://publicacoes.fcc.org.br/ ojs/index.php/cp/article/view/714/730

D’Ambrosio, U. (2001). Paz, educação matemática e etnomatemática. Teoria e Prática da Educação, 4, 15-33.

Dusi, M. L. H. M., Araújo, C. M. M., \& Neves, M. M. B.J . (2005). Cultura da paz e psicologia escolar no contexto da instituição educativa. Cultura da paz e psicologia escolar, 9(1), 135-145. Recuperado de http://pepsic.bvsalud.org/scielo.php?pid=S1413$85572005000100013 \&$ script=sci_arttext\&tlng=es

Fischmann, R. (2001). Educação, direitos humanos, tolerância e paz. Paidéia, 11(20), 67-77. doi: 10.1590/ S0103-863X2001000100008

Fischmann, R. (2007). Injustiça, autonomia moral e organização escolar: análise exploratória de relações. Paidéia, 17(38), 321-330. doi: 10.1590/S0103863X2007000300003

Foucault, M. (1999). Aula de 17 de março de 1976. In M. Foucault, Em defesa da sociedade. Tradução: Maria Ermantina Galvão (pp.285-316). São Paulo: Martins Fontes.

Kauth, A. R., Magallanes, L. M., Quintana, M. E. L., Díaz, J, \& Ramallo, S. L. (1988). Aporte experimental por el desarme y la paz: una experiência actitudinal. Arquivos Brasileiros de Psicologia, 40(1), 43-57. Recuperado de http://bibliotecadigital.fgv.br/ojs/index.php/abp/ article/view/20287/19027

Lèvy, A. (2004). Pensar a violência ou os limites do político. Psicologia em Revista, 10(16), 191-209. Recuperado de http://periodicos.pucminas.br/index.php/ psicologiaemrevista/article/view/208/219

Loos, H., \& Zeller, T. J. V. (2007). Aprendendo a "brigar melhor": Administração de conflitos sem violência na escola. Revista Interação em Psicologia, 11(2), 281-289. doi: 10.5380/psi.v11i2.7471

Maldonado, M. T. (1988). Caminhos da prevenção da violência doméstica e escolar: construindo a paz. Adolescência Latino-americana, 1(2), 111-117.
Mendonça, K. M. L. (2009). Entre a dor e a esperança: educação para o diálogo em Martin Buber. Memorandum, 17, 45-59. Recuperado de http://www.fafich.ufmg. $\mathrm{br} / \sim$ memorandum/a17/mendonca01.htm

ONU - Organização das Nações Unidas. (2016). Brasil tem a nona maior taxa de homicídios das Américas, alerta Organização Mundial da Saúde. Recuperado de https:// nacoesunidas.org/brasil-tem-a-nona-maior-taxa-dehomicidios-das-americas-alerta-oms/

Plon, M. A. (2004). Paz Eterna? Ágora, 7(1), 9-21. Recuperado de http://www.scielo.br/pdf/agora/v7n1/v7n1a01.pdf

Romesin, H. M., \& Yanes, X. P. D. (2004). Ética e desenvolvimento sustentável - caminhos para a construção de uma nova sociedade. Psicologia \& Sociedade, 16(3), 102-110. doi: 10.1590/S010271822004000300013

Sampaio, R. F., \& Mancini, M. C. (2007). Estudos de revisão sistemática: um guia para síntese criteriosa da evidência científica. Revista Brasileira de Fisioterapia, 11(1), 83-89. doi: 10.1590/S1413-35552007000100013

Souza, L. K. (2007). Educação para a paz e educação moral na prevenção à violência. Psicologia da Educação, 25, 131-155. Recuperado de http://pepsic.bvsalud.org/pdf/ psie/n25/v25a08.pdf

Souza, L. K., Mocelim, L. P., Trindade, F. B., \& Sperb, T. M. (2006). Psicologia e paz: a perspectiva de estudantes universitários. Arquivos Brasileiros de Psicologia, 58(1), 12-20. http://146.164.3.26/index.php/abp/article/ view/8/14

Souza, L. K., \& Sperb, T. M. (2006). Assimetria entre paz, guerra e violência na concepção de crianças e adolescentes. Psico-USF, 11(1), 219-227. http://www. scielo.br/pdf/pusf/v11n2/v11n2a10

Shincariol, M. F., \& Vasconcellos, A. C. (2001). Suporte psicossocial a familiares de militares durante operação de manutenção de paz. Psicologia: teoria e prática, 3(2), 37-45. Recuperado de http://editorarevistas.mackenzie. br/index.php/ptp/article/viewFile/1088/801 